\title{
Juvenile xanthogranuloma: Case report and review of the literature
}

\author{
Tatiana Karine Simon Cypel MD, Ronald Melvin Zuker MD FRCSC FACS FAAP
}

TKS Cypel, RM Zuker. Juvenile xanthogranuloma: Case report and review of the literature. Can J Plast Surg 2008;16(3):175-177.

The present case report describes a juvenile xanthogranuloma in a five-month-old girl. A circumscribed papule was located below the right nasal ala and above the right vermilion border. The lesion was histologically diagnosed as a juvenile xanthogranuloma after surgical resection of the mass. Juvenile xanthogranuloma is an uncommon diagnosis, with the head, neck and trunk being the most common sites.

\section{Key Words: Juvenile xanthogranuloma; Superior lip}

Tuvenile xanthogranuloma (JXG) is a member of the nonLangerhans cell group of histiocytic proliferative disorders (1), and is a relatively uncommon benign cutaneous fibrohistiocytic lesion. JXG was first reported by Adamson (2). In general, this is a regressing or stabilizing disorder usually occurring in infancy. It is characterized by one or more cutaneous nodules and less often by additional lesions in the deeper soft tissue or organs themselves.

Although the head, neck and trunk are the most common sites for JXG, it can appear anywhere on the body, including the groin, scrotum, penis, clitoris, eyelid, toenail, palms, soles and lips (3). Extracutaneous involvement is usually restricted to the eye, specifically the iris, but may also occur in bone, (Erdheim-Chester disease), lung and liver.

It is present at birth in $5 \%$ to $17 \%$ of the cases but it mainly arises within the first year of life (4). We present a case report of a baby girl with JXG localized in the upper lip.

\section{CASE PRESENTATION}

A five-month-old female fraternal twin, born at 38 weeks' gestational age, presented with a nodular lesion on her face, above the lip. The lesion had rapidly enlarged since it was first noted at three months of age. She had no abnormality at birth or history of any trauma. Occasional bleeding from the surface of the lesion was reported by the parents.

On physical examination, the lesion presented as a circumscribed papule, $6 \mathrm{~mm}$ in diameter and located just below the right nasal ala and above the right vermilion border of the upper lip (Figure 1). It was shiny, with some evidence of telangectasia and scaling located centrally. On palpation, it was a firm mass but did not extend to the oral mucosa. The alveolus and palate were completely normal.

The ultrasound report revealed that the lesion was most likely a hemangioma, and suggested a biopsy be performed to

\section{Xanthogranulome juvénile : exposé de cas et examen de la documentation}

\begin{abstract}
Suit un exposé de cas sur un xanthogranulome juvénile observé chez une petite fille de cinq mois. Une papule circonscrite est apparue sous l'aile nasale droite, au-dessus du bord libre de la lèvre, du côté droit. Un diagnostic histologique de xanthogranulome juvénile a été posé après la résection chirurgicale de la masse. Il s'agit d'une affection rare, qui touche le plus souvent la tête, le cou et le tronc.
\end{abstract}

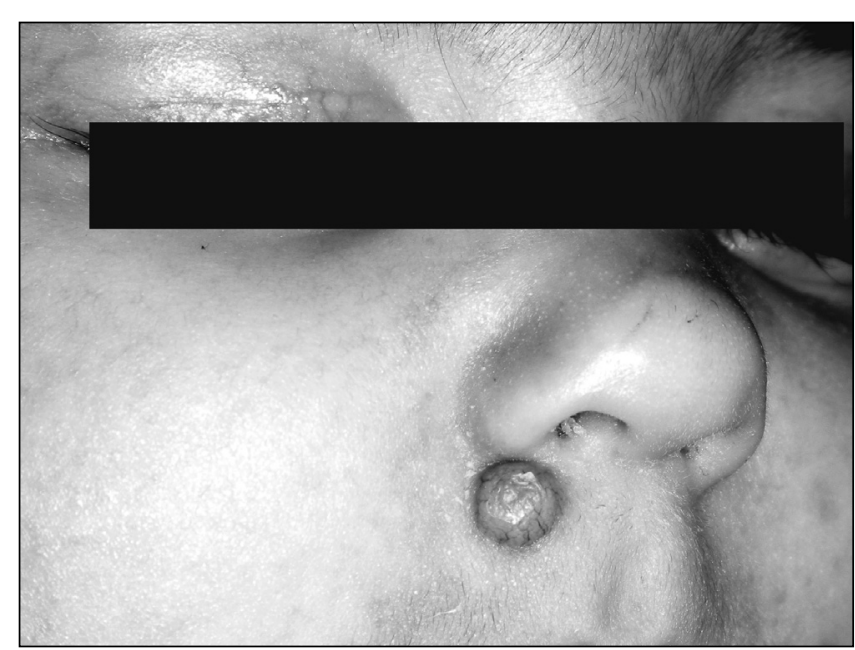

Figure 1) Preoperative appearance of the lesion

confirm the diagnosis. The patient underwent a shaved biopsy under general anesthesia. Histological evaluation of the lesion revealed a dense infiltrate of benign polygonal to spindleshaped fibroblastic cells, mixed with numerous foamy histiocytes within the papillary dermis, including multiple Touton cells with foamy, vacuolated cytoplasm. There were also scattered lymphocytes. The immunohistochemistry analysis demonstrated that the histiocytic cells were positive for CD68, but negative for CD1a, S-100 and Langerin. These combined results confirm that the histiocytes are non-Langerhans cells. In light of the clinical and histological findings, a diagnosis of JXG was made. The shaved biopsy site epithelialized uneventfully (Figure 2) and resulted in an acceptable minimal scar (Figure 3).

The Hospital for Sick Children, Toronto, Ontario

Correspondence and reprints: Dr Ronald Melvin Zuker, Division of Plastic Surgery, The Hospital for Sick Children, 555 University Avenue,

Toronto, Ontario M5G 1X8. Telephone 416-813-6447, fax 416-813-6147, e-mail ronald.zuker@sickkids.ca 


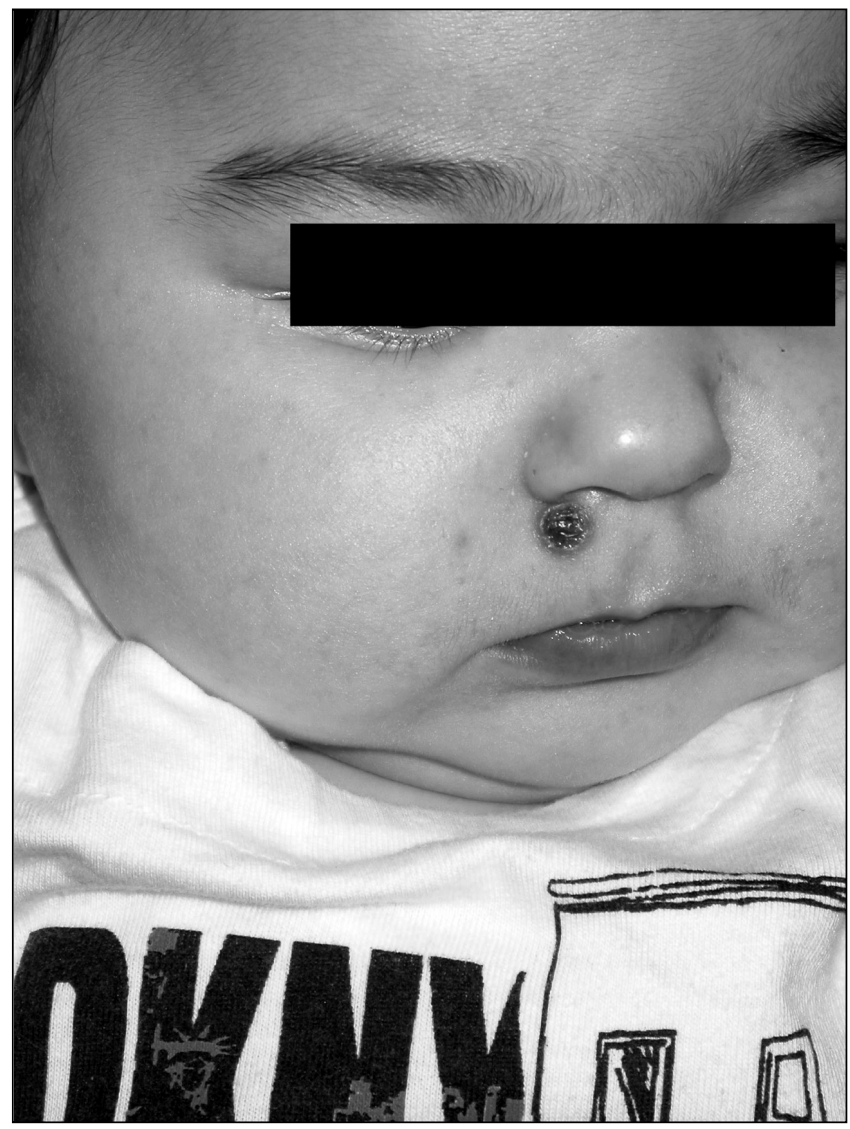

Figure 2) One week following surgical resection

\section{DISCUSSION}

Histiocytic disorders are currently identified by their component cells. In the right clinical context, lesional cells that are CD1a+/Langerin+/S100+ can be identified as Langerhans cell histiocytosis (LCH) without looking for ultrastructural Birbeck granules. A standard nonautomated avidin-biotin peroxidase complex method without antigen retrieval was used in the immunohistochemical analysis to explore the immunoreactivity to those antibodies. The non- $\mathrm{LCH}$ are a diverse group of disorders defined by the accumulation of histiocytes that do not meet phenotypic criteria for the diagnosis of Langerhans cells. Although some may have a hemophagocytic component, the definition excludes primary and secondary forms of hemophagocytic lymphohistiocytosis (5).

JXG is a benign cutaneous fibrohistiocytic lesion and a type of granulomatous process, at times accompanied by lipid deposits. Adamson (2), who first described this lesion in 1905 , defined single or multiple cutaneous nodules in infancy as congenital xanthoma multiplex. The lesions were designated nevoxanthoendothelioma by Mc Donagh in 1912 (6), who considered this disorder to be derived from endothelial cells. However, widespread recognition of an entity resembling JXG occurred in 1954 (7).

A solitary cutaneous lesion is the most common presentation but it may occur as a soft tissue lesion with or without organ involvement (1). JXG has been documented in many visceral locations such as lung, bone, testis, gastrointestinal tract, heart, eye and oral cavity (8-10). It can manifest as a multisystem disease $(1,11)$. The intramuscular lesions tend to be larger than cutaneous ones.

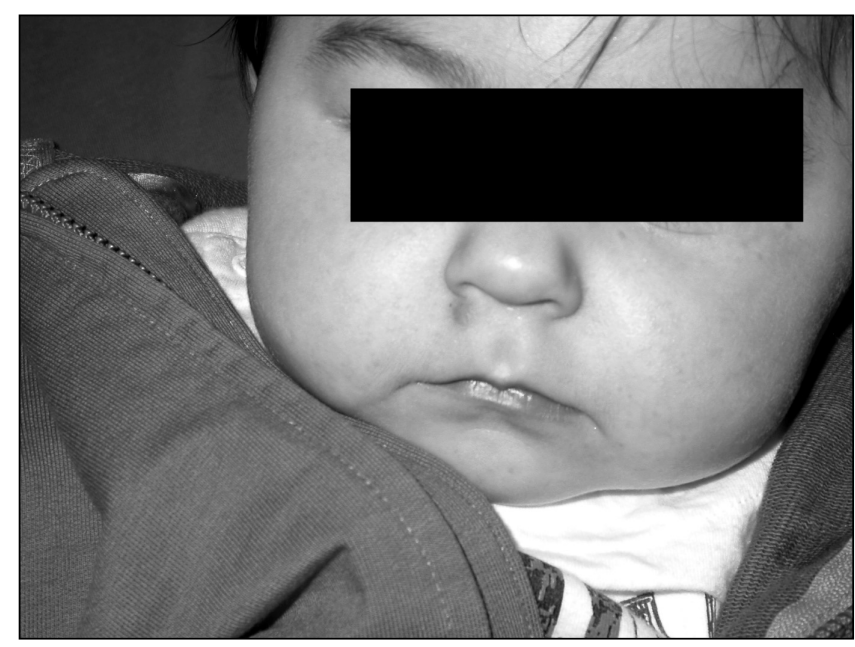

Figure 3) One month after surgery

JXG is a disease of the young child. Median age of onset is two years, but lesions may be present at birth. Lesions vary in size, but children younger than six months of age tend to present with multiple lesions with predominance in the head and neck. The male preponderance is much higher $(12: 1)$ in young infants with multiple skin lesions (1).

JXG is associated with other diseases including neurofibromatosis type 1 and juvenile chronic myelogenous leukemia (3). Ocular JXG occurs in the very young child, with $92 \%$ of patients being younger than two years of age, and may occur without concomitant skin involvement (15). Eye involvement is usually but not always unilateral, and commonly presents with an asymptomatic iris tumour, a red eye with signs of uveitis, unilateral glaucoma, spontaneous hyphema or heterochromia iridis (3). Other areas of the eye may be less commonly involved. Early diagnosis and treatment determine the final visual outcome. The diagnosis should not depend on finding typical lesions, and JXG should be part of the differential diagnosis of young children presenting with unilateral hyphema, glaucoma or exophtalmos.

JXG can be differentiated from xanthoma by the distribution of the lesion and the absence of lipid abnormalities. Three other differential diagnoses include molluscum contagiosum (pearly, dome-shaped papule with central umbilication), hemangioma and neurofibroma (firm lesion, associated caféau-lait spots) (17).

Histopathology is used to diagnose the presence of a non$\mathrm{LCH}$, but differentiation between the different subtypes is based mostly on immunohistochemistry and the clinical setting.

The basic histopathology of the non-LCH shows well circumscribed nodules with dense infiltrates of histiocytes. Those that involve the skin usually infiltrate the dermis. Giant multinucleate cells are variable in number and there is also a variable degree of predominantly perivascular and perilesional inflammatory cells. Touton giant cells (seen in $85 \%$ of cases of JXG, in a recent series) (1), are characterized by a wreath of nuclei around a homogeneous eosinophilic cytoplasmic centre, while the periphery shows prominent xanthomatization. Electron microscopy has revealed a variety of nonspecific organelles including dense bodies, worm-like bodies and popcorn bodies, among others (16). The cells of histiocytes and giant cells are monocyte-machophage in origin. They label 
strongly with macrophage markers such as CD 68 and HAM. On the other hand, S-100 protein immunoreactivity, which is a marker for the diagnosis of LCH, is typically absent $(18,19)$.

JXG is most often a self-limiting disease that often spontaneously regress $(1,4,8-11)$. Lesions may resolve completely or may leave a residual atrophic or hyperpigmented scar. The pathogenesis is unknown, and the initiating stimuli may be one of many infections or physical factors $(13,14)$. Conservative management of these tumours has been advocated (12). Despite the likelihood of spontaneous regression, it is often decided to excise the lesion(s) for esthetic or diagnostic reasons, as was the case for our patient. Excision of the lesion is an adequate treatment and recurrence is uncommon, although it has been documented $(18,20)$.

It is our recommendation that enlarging soft tissue masses in children in whom a malignancy cannot be excluded by physical or radiological examination be biopsied, including total excision when no functional compromise from surgery is anticipated.

\section{REFERENCES}

1. Dehner LP. Juvenile xanthogranuloma in the first decades of life. A clinicopathologic study of 174 cases with cutaneous an extracutaneous manifestations. Am J Surg Pathol 2003;5:579-93.

2. Adamson HG. Society intelligence: The Dermatological Society of London. Br J Dermatol 1905;17:222.

3. Hernandez-Martin A, Baselga E, Drolet BA, Esterly NB. Juvenile xanthogranuloma. J Am Acad Dermatol 1997;36:335-67.

4. Jung T, Emmert S, Günzl HJ, Neumann C, Rünger TM. [Congenital manifestations of juvenile xanthogranuloma (large nodular form)]. Hautarzt 2000;51:423-6.

5. Sheila W, Ronald J. Uncommon histiocytic disorders: The nonLangerhans cell histiocytoses. Pediatr Blood Cancer 2005;45:256-64.

6. Mc Donagh JER. A contribution to our knowledge of the naevoxantho-endotheliomata. Br J Dermatol 1912;24:85-99.
7. Helwig EB, Hackney VC. Juvenile xanthogranuloma (nevoxanthoendothelioma). Am J Pathol 1954;30:625-6.

8. Margulis A, Lelin-Aldana H, Bauer BS. Juvenile xanthogranuloma invading the muscles in the head and neck: Clinicopathological case report. Ann Plast Surg 2003;50:425-8

9. Lesniak MS, Viglione MP, Weingart J. Multicentric xanthogranuloma in a child: Case report and review of the literature. Neurosurgery 2002;51:1493-8.

10. Cusik EL, Spicer RD. Juvenile xanthogranuloma with extracutaneous lesion - a case report. Eur J Pediatr Surg 1994:4:368-9.

11. Freyer DR, Kennedy R, Bostrom BC, et al. Juvenile xanthogranuloma: Forms of systemic disease and their clinical implications. J Pediatr 1996;129:223-7.

12. Cornelia H, Mona EB, Gordon S, Abel RM. Juvenile xanthogranuloma: A case report of a preterm baby. J Pediatr Surg 2006;41:573-5.

13. Chang MW. Update on juvenile xanthogranuloma: Unusual cutaneous and systemic variants. Semin Cutan Med Surg 1999;18:195-205.

14. Zvulunov A, Barak Y, Metzker A. Juvenile xanthogranuloma, neurofibromatosis, and juvenile chronic myelogenous leukemia. World statistical analysis. Arch Dermatol 1995;131:904-8.

15. Chang MW, Frieden IJ, Good W. The risk of intraocular juvenile xanthogranuloma: Survey of current practices and assessment of risk. J Am Acad Dermatol 1996;34:445-9.

16. Wee SH, Kim HS, Chang SN et al. Generalized eruptive histiocytoma: A pediatric case. Pediatric Dermatol 2000;17:453-5.

17. Kesavan TM, Sreedevi PK. Juvenile xanthogranuloma. Indian Pediatr 2005;42:950.

18. Sonoda T, Hashimoto H, Enjoji M. Juvenile xanthogranuloma. Clinicopathologic analysis and immunohistochemical study of 57 patients. Cancer 1985;56:2280-6.

19. Zelger B, Cerio R, Orchard G, Wilson-Jones E. Juvenile and adult xanthogranuloma. A histological and immunohistochemical comparison. Am J Surg Pathol 1994;18:126-35.

20. Cohen BA, Hood A. Xanthogranuloma: Report on clinical and histologic findings in 64 patients. Pediatr Dermatol 1989;6:262-6. 